\title{
Effect of Al addition to Rapidly Solidified Mg-Cu-Rare Earth Alloys
}

\author{
Silvia Rozenberg ${ }^{a}$, Fernando Audebert $^{a, b, c}$, ,Marina Galano ${ }^{c}$, Isabel Vergara Ogando ${ }^{d}$,
}

\author{
Cecilia Mendive
}

\author{
${ }^{a}$ Advanced Materials Group, Institute of Technology and Engineering Sciences - INTECIN, Faculty of \\ Engineering, University of Buenos Aires, Paseo Colón 850, Ciudad de Buenos Aires, 1063, Argentina \\ ${ }^{b}$ Department of Mechanical Engineering and Mathematical Sciences, Oxford Brookes University, \\ Wheatley Campus, OX33 1HX, Oxford, United Kingdom \\ ${ }^{c}$ Department of Materials, University of Oxford, 16 Parks Road, OX1 3PH, Oxford, United Kingdom \\ ${ }^{d}$ Department of Physics, Universidad Carlos III, C/Butarque 15, Leganes, 28911, Madrid, Spain \\ ${ }^{e}$ Department of Chemistry, University of Mar del Plata, Dean Funes 3350, Mar del Plata, B7602AYL, Argentina
}

Received: January 21, 2016; Revised: April 17, 2016; Accepted: April 27, 2016

\begin{abstract}
Rapidly solidified Mg based alloys are of interest for industrial applications as a structural material and for hydrogen storage. $\mathrm{Mg}$-Cu-Rare Earth alloys have shown high glass forming ability; full amorphous structure with thickness of $\mathrm{mm}$ size can be obtained within these systems. However, their brittle behavior limits their industrial applications. In the present work, the Al effect in substitution of $\mathrm{Cu}$ in the $\mathrm{Mg}_{65} \mathrm{Cu}_{25} \mathrm{MM}_{10}$ (at\%, MM: mischmetal) was studied. Samples up to $15 \mathrm{at} \% \mathrm{Al}$ were prepared by splat cooling and their microstructure, stability and mechanical properties were characterised. The crystallization temperature increases with the $\mathrm{Al}$ addition; the amorphous phase with different $\mathrm{Al}$ content has a Young's modulus of $\sim 55 \mathrm{GPa}$; the microhardness increases with the $\mathrm{Al}$ content in the amorphous and crystallized samples and the fracture of the alloy containing 10 at $\% \mathrm{Al}$ showed ductile vein patterns characteristics of ductile metallic glasses. The partial $\mathrm{Cu}$ substitution by $\mathrm{Al}$ can improve the stability and mechanical properties of the amorphous $\mathrm{Mg}_{65} \mathrm{Cu}_{25} \mathrm{MM}_{10}$ alloy.
\end{abstract}

Keywords: Magnesium, Rapid Solidification, Amorphous

\section{Introduction}

Rapid solidified Mg based alloys are of interest for industrial applications as a structural material and also for hydrogen storage. Particularly, Mg-Cu-(Y or RE), (RE: rare earths) alloys have shown very high glass forming ability, some of them can be obtained with full amorphous structure with thickness at mm size, which are called Mg based Bulk Metallic Glasses $(\mathrm{BMGs})^{1,2}$. The highest glass forming ability was found at the eutectic composition of the $\mathrm{Mg}_{65} \mathrm{Cu}_{25} \mathrm{Y}_{10}$ alloy ${ }^{1,3}$. BMGs have very high strength compared to their crystalline counterparts because of having no dislocations. However, they normally show a brittle behaviour. Fracture toughness values less than $10 \mathrm{MPa} \cdot \mathrm{m}^{1 / 2}$ were observed for Mg-based BMGs ${ }^{4,5}$, which practically represent an ideal brittle behaviour as it is normally associated with oxide glasses.

The metallic glasses fail by forming intense shear bands which propagate catastrophically due to the lack of grain structure and work hardening ${ }^{6,7}$. Early works on the fracture behaviour of metallic glasses noted the presence of voids and vein patterns on fracture surfaces ${ }^{8,9}$, indicating the activation of flow processes and suggesting that fracture may occur via micro-voids coalescence; however, as the deformation takes place extremely localised through shear bands practically no macroscopy plasticity is observed. $F$. Spaepen ${ }^{10}$ first proposed the free volume theory to account for the deformation in metallic glasses, in which the deformation

*e-mail:metal@fi.uba.ar is localized and this localization will give rise to the change of viscosity and finally results in the inhomogeneous plastic flow. To overcome such brittle behaviour different strategies were applied to improve the ductility of BMGs, achieved by increasing the number of shear bands along the volume of the material allowing a more homogenous deformation and extended macroscopy plasticity. The different strategies for this mechanism can be summarized as:

(i) Introducing shear bands by means of mechanical deformation, an increase in homogeneous deformation was observed after cold rolling ${ }^{11}$.

(ii) Introducing long scale heterogeneities, such as partial crystallization of an intermetallic phase or manufacturing composites containing for example, ceramic particles ${ }^{12}$, ductile metals ${ }^{13-15}$ and even $\alpha-\mathrm{Mg}$ solid solution ${ }^{16}$ as a second phase component.

(iii) Microalloying to increase the Poisson ratio. $H$. S. Chen et $a l^{17}$ were the first authors who suggested that the higher Poisson ratio of an amorphous alloy allows the ease atomic regrouping leading to the ductile plastic deformation in the metallic amorphous phase. A higher Poisson ratio decreases the potential energy of the shear transformation zone, thereby increasing the tendency of plastic deformation in mitigating the fracture stress concentration. More recently, J. Lewandowski et all found a clear correlation for BMGs between fracture energy $G$ and the elastic ratio $\mu / B$, where $\mu$ is the elastic shear modulus and $B$ the bulk modulus. They found that BMGs with higher values of $(\mu / \mathrm{B})_{\text {crit }}=0.41-0.43$ have a brittle behaviour, which is equivalent to Poisson ratio values 
below $v=0.31-0.32$. Thus, they suggest that the brittleness in BMGs can be alleviated by alloying with elements with low $\mu / \mathrm{B}$ (or, equivalently, high $v$ ) as constituents.

(iv) Microalloying to produce the amorphous phase separation $^{19}$. This was achieved in some BMGs by adding elements with a large difference in its mixing enthalpy when binding with the main elements of the alloy. Phase separation results in some areas with different chemical compositions, different coordination numbers and different nearest atomic numbers ${ }^{20}$. Thus, yielding to a structure composed by two amorphous phases that have different critical shear stress, which facilitate the shear bands formation. When yielding, the relatively soft phase will have more free volume and will deform and shear, preferentially. For example, X.H. Du et $a l^{19}$ determined the best $\mathrm{Zr}_{63.8} \mathrm{Cu}_{16.2} \mathrm{Ni}_{15} \mathrm{Al}_{5} \mathrm{BMG}$ composition with the dual amorphous structure using the thermodynamic calculation method. The experimental results indicated that there are two kinds of $\mathrm{Cu}$-rich and Ni-rich amorphous phases together and the macro-compressive plasticity strain can reach $30 \%$. However, the dual amorphous phase is not a sufficient condition for plasticity as observed by E. Park and D.H. $\mathrm{Kim}^{21}$. They found that in the $\mathrm{Cu}_{46} \mathrm{Zr}_{47-\mathrm{x}} \mathrm{Y}_{\mathrm{x}} \mathrm{Al}_{7}$ system, when the content of $\mathrm{Y}$ is higher than $15 \mathrm{at} \%$, the dual amorphous phases are very brittle, while the monolithic BMG $(x=2.5)$ has a good ductility. The complementary condition could be related with the atomic binding energy in both amorphous phases, at least one of them should be weak to allow atomic displacements under the condition of an applied load.

(v) Microalloying to produce a heterogeneous amorphous phase $^{22}$. It is a similar criterion to the amorphous phase separation that considers chemical fluctuations in a medium range due to the formation of strong hetero-atomic clusters which are distributed in a more disordered amorphous matrix richer in the major alloy's component. This type of amorphous phase can be observed in alloys with large fraction of the main component of the alloy, for example in Al- or Mg-based alloys $\mathrm{s}^{23}$. F. Audebert \& col. have studied several Al-Fe and Al-Ni based alloys with $\mathrm{Al}$ content higher than $85 \mathrm{at} \% \mathrm{o}^{23-27}$. They found that amorphous phases with this heterogeneous characteristic show a pre-peak at low angle in the X-ray diffractogram, which is related with the strong chemical short range order due to the hetero-atomic clusters. Thus, they proposed to reduce the fraction of the strong hetero-atomic clusters by substitution of one of the alloying elements in the clusters for another element with less binding energy with the major component in the alloy. In addition this element should dissolve easily in the remaining amorphous fraction.

Among all the strategies for increasing plasticity in amorphous phases and particularly in BMGs the last two strategies, (iv) and (v), preserve a fully amorphous material without introducing damages such as shear bands by mechanical processes. In an early work the authors observed that the fracture surface turned from featureless to a "vein pattern" features when $10 \mathrm{at} \% \mathrm{Cu}$ is substituted by $\mathrm{Al}$ in a $\mathrm{Mg}_{65} \mathrm{Cu}_{25} \mathrm{RE}_{10}$ amorphous alloy ${ }^{22}$. In the present work, following the microalloying strategy for heterogeneous amorphous phase $(\mathrm{v})$, the effect of different fractions of $\mathrm{Al}$ in substitution of $\mathrm{Cu}$ in a $\mathrm{Mg}_{65} \mathrm{Cu}_{25} \mathrm{RE}_{10}$ on the glass forming, thermal stability, mechanical properties and the possible improvement on it plasticity were studied.

\subsection{Experimental Procedure}

Master alloys were prepared from pure elements and mischmetal (MM) with $54 \% \mathrm{Ce}$ and $27 \% \mathrm{La}$, in an electric furnace by diffusion of $\mathrm{Cu}$ and $\mathrm{MM}$ or $\mathrm{Y}$ particles in a molten $\mathrm{Mg}-\mathrm{Al}$ alloy at $950^{\circ} \mathrm{C}$, using a graphite crucible under Argon atmosphere. Rapidly solidified (RS) samples up to $15 \mathrm{at} \% \mathrm{Al}$, with compositions summarized in Table 1, were prepared by the splat cooling technique in Argon atmosphere. The microstructure and stability were characterised by means of X-ray diffraction with $\mathrm{Cu}-\mathrm{K} \alpha$ radiation in a $\theta-2 \theta$ Rigaku diffractometer, and differential scanning calorimetry (DSC) at $40 \mathrm{~K} / \mathrm{min}$ of heating rate under Ar flow in a Piris 1 Perkin Elmer calorimeter. Heat treated samples were prepared by annealing under Ar atmosphere for 10min at the peak temperature of the first crystallization step. The mechanical properties were characterised by microhardness with $50 \mathrm{~g}$ in a HV2000 Shimadzu micro-indenter, and by nano-indentation to obtain the Young's modulus. The samples were fractured by bending in a cantilever beam arrangement and the fracture analysis was performed by means of scanning electron microscopy in a JEOL 6510 LV microscope.

Table 1: Alloys' code and compositions.

\begin{tabular}{lc}
\hline Alloy Code & Alloy Composition (at \%) \\
\hline $\mathrm{Y}$ & $\mathrm{Mg}_{65} \mathrm{Cu}_{25} \mathrm{Y}_{10}$ \\
Al-0 & $\mathrm{Mg}_{65} \mathrm{Cu}_{25} \mathrm{MM}_{10}$ \\
Al-5 & $\mathrm{Mg}_{65} \mathrm{Cu}_{20} \mathrm{Al}_{5} \mathrm{MM}_{10}$ \\
Al-10 & $\mathrm{Mg}_{65} \mathrm{Cu}_{15} \mathrm{Al}_{10} \mathrm{MM}_{10}$ \\
Al-15 & $\mathrm{Mg}_{65} \mathrm{Cu}_{10} \mathrm{Al}_{15} \mathrm{MM}_{10}$ \\
\hline
\end{tabular}

The "Y" alloy is the monolithic Mg-BMG alloy that is used in this work as a standard material, and was manufactured with the same procedure that the rest of the MM-containing alloys in order to control manufacturing parameters and to compare the effect in the amorphous phase properties of use MM instead of Y.

\section{Results and Discussion}

\subsection{Microstructural Characterisation}

Figure 1(a) shows the X-ray diffractograms of the rapidly solidified samples. Y, Al-0, Al-5 and Al-10 samples showed an amorphous phase characterized by a main broad peak at around $2 \theta \sim 36.4^{\circ}$ for the $\mathrm{Y}$ and $\mathrm{Al}-0$ alloys that slightly shifted to lower angles, $2 \theta \sim 34.7^{\circ}$ as the $\mathrm{Al}$ content increases. This behaviour is expected as the metallic atomic radius of $\mathrm{Al}$ $\left(\mathrm{r}_{\mathrm{at}} \sim 0.143 \mathrm{~nm}\right)$ is larger than the metallic atomic radius of $\mathrm{Cu}$ $\left(\mathrm{r}_{\mathrm{at}} \sim 0.128 \mathrm{~nm}\right)$. The average $\mathrm{Mg}-\mathrm{Al}$ atomic distance is larger than the average $\mathrm{Mg}-\mathrm{Cu}$ atomic distance, thus the $\mathrm{Mg}-\mathrm{Al}$ pairs contribute with a diffraction intensity distribution at lower angle than the $\mathrm{Mg}-\mathrm{Cu}$ pairs, which shifts the main amorphous peak to lower angles. A little asymmetry in the main amorphous peak in the diffractograms of the Al-5 and Al-10 alloys is also observed. This could be a consequence of an intensification of the chemical heterogeneity of the amorphous structure or the formation of small fraction of 


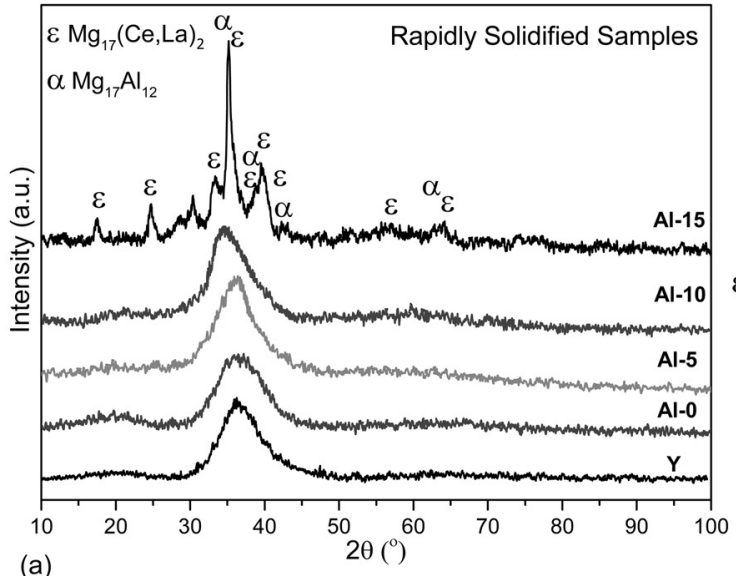

(a)

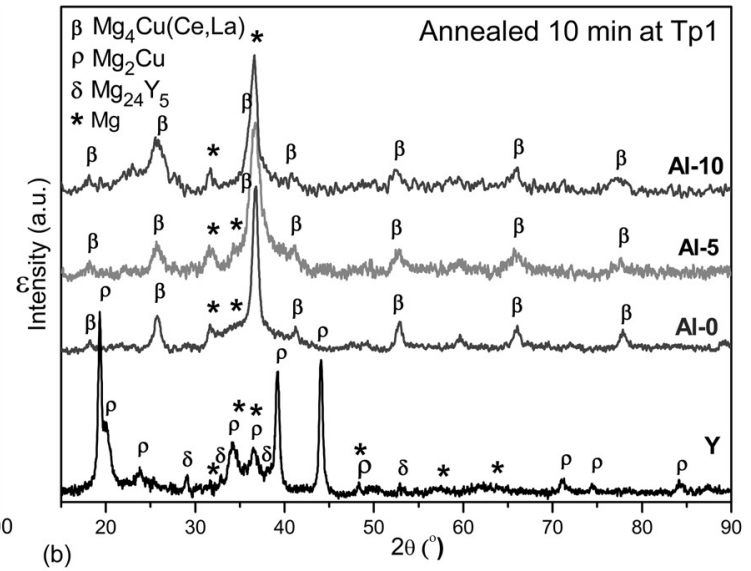

(b)

Figure 1: X-ray diffractograms of (a) rapidly solidified alloys and (b) heat treated samples.

crystalline order at the nanoscale. In addition, the diffractograms of the $\mathrm{Y}$ and $\mathrm{Al}-0$ showed a weak and broad pre-peak around $2 \theta \sim 20.3^{\circ}$, which reveals a strong chemical short and medium range order, as it was observed in the literature ${ }^{22,28,29}$. The $\mathrm{X}$-ray diffractograms of the $\mathrm{Al}-5$ and $\mathrm{Al}-10$ alloys do not show a clear pre-peak, which is in agreement with the criterion of the micro-alloying to reduce the fraction of the strong hetero-atomic clusters in the amorphous phase. Considering the highest electronegativity difference of 0.5 between $\mathrm{Mg}$ and $\mathrm{Cu}$ it is expected that $\mathrm{Mg}$-Cu rich clusters contribute to the pre-peak in the amorphous diffraction patterns. Thus, the partial substitution of $\mathrm{Cu}$ by $\mathrm{Al}$ reduces the intensity of the pre-peak, being the $\mathrm{Al}$ more randomly distributed.

The X-ray diffractogram of the rapidly solidified Al-15 sample shows several peaks revealing that for this composition the glass forming ability drastically decreases. Only some peaks with high intensity could be associated to $\mathrm{Mg}_{17}(\mathrm{Ce}, \mathrm{La})_{2}$ and $\mathrm{Mg}_{17} \mathrm{Al}_{12}$ phases, while other peaks couldn't be identified.

The partial substitution of $\mathrm{Cu}$ by $\mathrm{Al}$ up to $10 \mathrm{at} \%$ allows retaining the amorphous phase during rapid solidification, however when $15 \mathrm{at} \% \mathrm{Cu}$ is substituted by $\mathrm{Al}$ the glass forming ability (GFA) decreases drastically and crystalline phases are formed.

Figure 2 shows the DSC curves obtained for the rapidly solidified $\mathrm{Y}, \mathrm{Al}-0, \mathrm{Al}-5$ and $\mathrm{Al}-10$ alloys and Table 2 summarises the glass temperature $(\mathrm{Tg})$, crystallisation temperature (Tx) and the peak temperature of the first exothermic transformation. The DSC curve from the $\mathrm{Y}$ sample shows only one peak which would correspond to an eutectoid transformation as the alloy corresponds to the eutectic composition in agreement with the literature ${ }^{30}$.

The calorimetric analysis shows that the substitution of $Y$ by MM decreases the glass forming ability, reducing the undercooled liquid range $(\Delta \mathrm{T}=\mathrm{Tx}-\mathrm{Tg})$ and shifting the crystallization temperature (Tx) towards lower temperatures. It is known that the $\mathrm{Mg}_{65} \mathrm{Cu}_{25} \mathrm{Y}_{10}$ alloy is a ternary eutectic composition which crystallizes in only one exothermic peak ${ }^{31}$. Meanwhile the use of MM instead of Y shifts the alloy to an off-eutectic composition and the crystallization is developed through three steps. However,

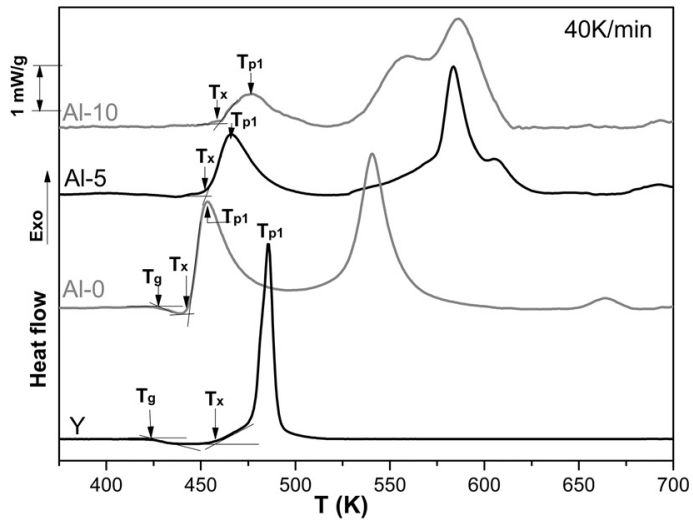

Figure 2: DSC curves of Y, Al-0, Al-5 and Al-10 rapidly solidified alloys.

Table 2: Glass Temperature (Tg), onset crystallization Temperature (Tx) and peak Temperature of the first crystallization step (Tp1).

\begin{tabular}{lccc}
\hline Alloy & Tg $(\mathrm{K})$ & $\mathrm{Tx}(\mathrm{K})$ & $\mathrm{Tp} 1(\mathrm{~K})$ \\
\hline Y & 425 & 457 & 485.5 \\
Al-0 & 427 & 442.5 & 453.5 \\
Al-5 & ---- & 453 & 466 \\
Al-10 & ---- & 459.5 & 476 \\
\hline
\end{tabular}

not all the RE have the same effect on the crystallization process, for example, when $\mathrm{Y}$ is substituted by Gd the crystallization is still developed through only one step but with the crystallization temperature shifted to lower values $^{31,32}$.

The addition of $\mathrm{Al}$ in substitution of $\mathrm{Cu}$ reduces the GFA as the Tg is not observed in the DSC curves. On the other hand, the onset of the crystallization (Tx) is shifted to higher temperatures, which means that the $\mathrm{Al}$ addition increases the stability of the amorphous phase. The crystallization process in the Al-containing alloys becomes more complex than the crystallization process of the $\mathrm{Mg}_{65} \mathrm{Cu}_{25} \mathrm{MM}_{10}$ amorphous alloy. The second exothermic step shows peaks overlapping 
that suggest that a chain of phase transformation occurs in a short range of temperatures. Table 2 summarizes $\mathrm{Tg}$, Tx and the peak temperature of the first crystallization step (Tp1).

The X-ray diffractograms of the heat treated samples show that the crystallization for the $\mathrm{Mg}_{65} \mathrm{Cu}_{25} \mathrm{Y}_{10}$ alloy starts with the formation of the $\mathrm{Mg}_{2} \mathrm{Cu}$, hcp- $\mathrm{Mg}$ and $\mathrm{Mg}_{24} \mathrm{Y}_{5}$ as observed by several authors ${ }^{33,34}$. However, in all the alloys studied containing $\mathrm{MM}$ (with or without $\mathrm{Al}$ ) the crystallization started with the same phases, $\mathrm{Mg}$ and $\mathrm{Mg}_{4} \mathrm{Cu}(\mathrm{Ce}, \mathrm{La})$ as can be seen in Figure 1.b. This fact suggests that the first crystallization step is driven by the original elements $(\mathrm{Mg}, \mathrm{Cu}$ and $\mathrm{RE}$ ), meanwhile the $\mathrm{Al}$ addition only affects the kinetic of the phase transformation by shifting the crystallization (Tx and Tp1) to higher temperatures, probably by hindering diffusion of the other elements in the alloy.

\subsection{Mechanical Properties}

As shown in Figure 3 the substitution of Y by MM increases the microhardness by $\sim 13 \%$ in the amorphous sample and by $\sim 9 \%$ in the heat treated samples up to a maximum average $\mu \mathrm{HV}_{50}$ value of 286 and 375 for the Al- 0 amorphous and the heat treated samples. Considering the first crystallization step in the Y and Al-0 alloys, in which the crystallized phases containing Y or RE are different, suggesting the existence of different type of hetero-atomic clusters containing Y or RE in the Y and Al-0 amorphous phases respectively. Therefore, the fact that the highest microhardness value is obtained for the MM-containing (Al-0) amorphous phase rather than for the Y-containing (Y) amorphous phase could be related with the different type of strong hetero-atomic clusters in the amorphous phase.

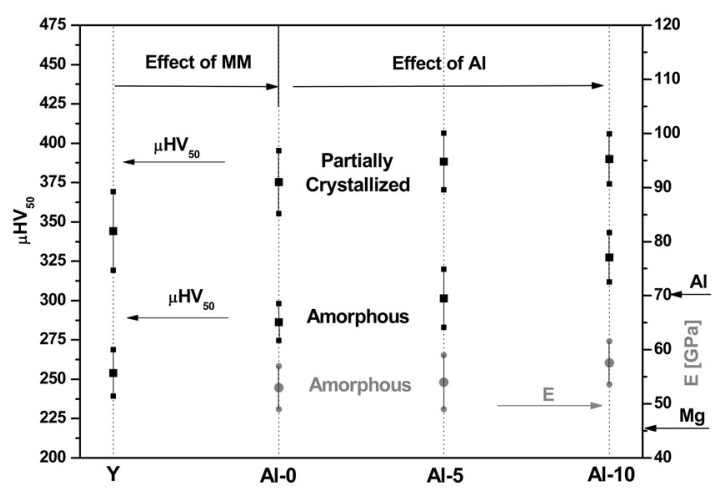

Figure 3: Vickers microhardness (black symbols) of the rapidly solidified amorphous alloys and the partially crystallised (by heat treatment) samples; and Young's modulus (grey symbols) of the amorphous samples.

The partial substitution of $\mathrm{Cu}$ by $\mathrm{Al}$ also increases the microhardness in the amorphous phase respect to the Al- 0 by $\sim 5.5 \%$ and $\sim 14.5 \%$ for the Al-5 and Al-10 alloys. Having the latter a maximum average value of $\mu \mathrm{HV}_{50}=327$. However, the microhardness of the partially crystallized samples remains practically constant for the Al-0, Al-5 and Al-10 alloys with an average value of $\mu \mathrm{HV}_{50} \sim 384$. Because of the change in the crystallization behaviour (Figure 2), the partially crystallised samples are composed of the same crystalline phases distributed in an amorphous matrix but with different chemical composition of the remained amorphous phase and different fractions of the crystalline phases. This difference in the microstructure among the partially crystallised Al-0, Al-5 and Al-10 samples can yield similar average microhardness values. B. Murty and K. Hono ${ }^{35}$ also found an increase in the microhardness when $\mathrm{Cu}$ is partially substituted by $\mathrm{Al}$ in the $\mathrm{Mg}_{65} \mathrm{Cu}_{25} \mathrm{Y}_{10}$.

The Young's modulus was measured by nanoindentation only in the amorphous samples. No appreciable change in the Young's modulus with the Al content is observed, having an average value of $\mathrm{E} \sim 55 \mathrm{GPa}$, which is in between of the corresponding values of the crystalline pure $\mathrm{Mg}(\mathrm{E}$ $=45 \mathrm{GPa})$ and pure $\mathrm{Al}(\mathrm{E}=70 \mathrm{GPa})$. Other authors found lower Young's modulus values for similar amorphous alloys, such as $\mathrm{Mg}_{65} \mathrm{Cu}_{25} \mathrm{X}_{10}, \mathrm{E} \sim 50 \pm 1 \mathrm{GPa}$ for $\mathrm{X}=\mathrm{Gd}, \mathrm{Y}$ or $\mathrm{Tb}^{36}$.

\subsection{Fracture Analysis}

Due to their brittleness, Mg-Cu-RE based amorphous alloys, cannot be plastically deformed at room temperature and normally show a typical featureless mirror fracture surface, which results from fast shear sliding that reflects the ideal brittle fracture mode, as observed for the Y alloy in Figure 4.a. The alloy Al-0, also shows a brittle fracture, but in this particular case, "Wallner lines" were developed (Figure 4.b). Such pattern has a periodic wave of $80 \mathrm{~nm}$ formed due to interactions between the stress field of crack propagation and elastic waves produced by the release of the fracture energy by acoustic emission.

As the $\mathrm{Al}$ fraction increases ductile features are observed in the fracture surface. Thus the Al-5 sample shows several slip bands with very little vein-pattern (Figure 4.c). This morphology occurs due to a rise of temperature in the shear bands that leads to decrease the viscosity locally and yields to a local ductility in the amorphous structure. With further increase in the $\mathrm{Al}$ content (Al-10) larger vein-patterns with small dimples shape can be seen in Figure 4.d. This fracture pattern demonstrates the ductility enhancement in the amorphous alloys obtained due to the partial substitution of $\mathrm{Cu}$ by $\mathrm{Al}$.

These results agree with the proposed strategy to increase ductility based in reducing the strong hetero-atomic clusters (thought as $\mathrm{Mg}_{2} \mathrm{Cu}$ type in this alloy) by chemical substitution.

With further increase of the Al content the glass formability decreases drastically and the crystalline phases are easily formed despite the rapid solidification process applied. Thus, the Al-15 alloy is mainly composed by crystalline phases (Figure 1.a), and has a brittle behaviour as can be observed in the fracture surface in Figure 4.e. The deformation of the A1-15 alloy appears to be trough slip bands as for the amorphous alloys. Slip bands were observed in the lateral surface of the sample as shown in Figure 4.f. In Al-15 the slip bands probably initiated at the sample's surface as can be observed in Figure 4.e where an arrow shows the mirror surface area of the shear sliding from surface towards the volume of the sample. Then, once a crack is initiated a fast fracture took place leaving a featureless flat fracture surface.

Some authors explained the brittleness due to a relaxation and aging process at room temperature ${ }^{37,38}$. A. Castellero et $a l^{37}$ showed a continue increase of hardness against time at 

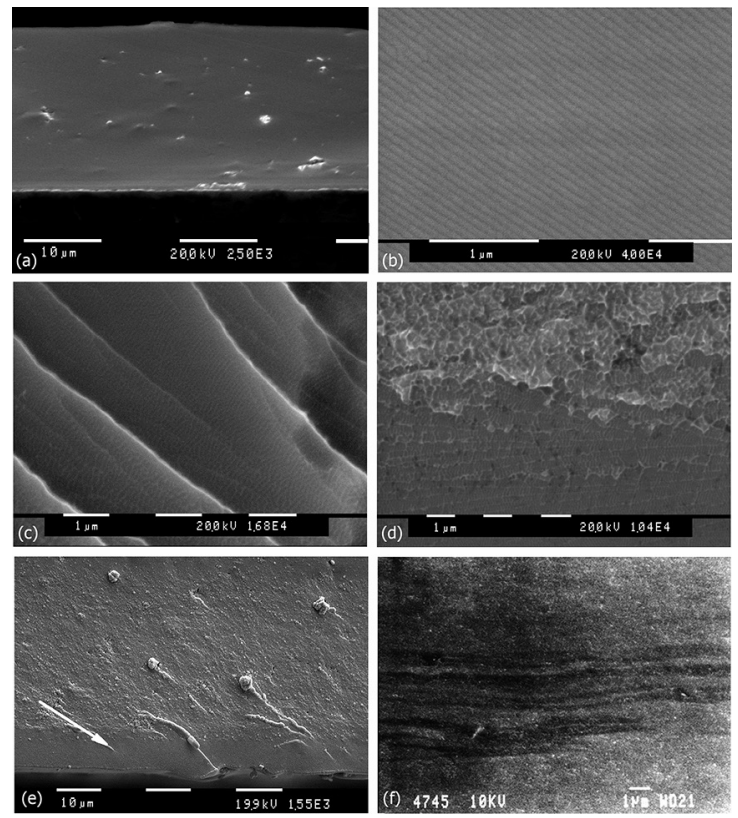

Figure 4: Facture Surfaces. (a) Y, brittle fracture, smooth surface; (b) Al-0, brittle fracture with "Wallner lines"; (c) Al-5, slip bands and vein-patterns; (d) Al-10, dimples and vein-pattern; (e) Al-15, arrow shows shear sliding; (f) Al-15 lateral side, slip bands.

room temperature for splat cooled $\mathrm{Mg}-\mathrm{Cu}-\mathrm{Y}$ samples using nano-indentation. They also performed internal friction measurements to study the structural relaxation at room temperature and they concluded that the relaxation process induces an abrupt embrittlement after periods of time that depend on the relative proportions of $\mathrm{Cu}$ and $\mathrm{Mg}$ in this alloy system. All these results suggest that the brittleness appears as an inherent property of the rapidly solidified $\mathrm{Mg}-\mathrm{Cu}-(\mathrm{Y} / \mathrm{RE})$ alloys due to a room temperature aging driven by a relaxation process. However, this effect can be delayed or hindered changing the $\mathrm{Cu} / \mathrm{Mg}$ ratio from the BMG monolithic composition of $\mathrm{Mg}_{65} \mathrm{Cu}_{25} \mathrm{Y}_{10}$ (at \%). These experimental achievements are aligned with the proposed conceptual strategy for increasing plasticity by micro-alloying to reduce the fraction of the strong hetero-atomic clusters in the amorphous phase, proposed by $F$. Audebert et $a l^{22}$. Based on this strategy, J. Y. Geng et al ${ }^{32}$ studied the $\mathrm{Mg}_{65} \mathrm{Cu}_{25}$ ${ }_{x} \mathrm{Al}_{\mathrm{x}} \mathrm{Gd}_{10}$ alloys and found the same ductility improvement in agreement with our results on $\mathrm{Mg}_{65} \mathrm{Cu}_{25-\mathrm{x}} \mathrm{Al}_{\mathrm{x}} \mathrm{MM}_{10}$ alloys.

The improvement in the ductility can be explained due to an increase in the slip bands density, thus producing a more homogeneous deformation avoiding the extremely localized shear sliding in the ideal brittle fracture. Localized shear events occur in the so-called shear transformation zones (STZs), which are small clusters of randomly close-packed atoms that spontaneously and cooperatively reorganize under the action of an applied shear stress ${ }^{39}$. Considering the heterogeneous amorphous structure of the $\mathrm{Mg}_{65} \mathrm{Cu}_{25}$ $\mathrm{Al}_{\mathrm{x}} \mathrm{MM}_{10}$ alloys, composed by strong $\mathrm{Mg}-\mathrm{Cu}$ rich clusters embedded in a softer matrix, the partial substitution of $\mathrm{Cu}$ by $\mathrm{Al}$ reduces the fraction of strong clusters and increases the softer areas where Al would be localized. The increase in slip bands density and ductility with the $\mathrm{Al}$ addition can be related with the increase of the softer area, which suggests this area acts as a source of STZs that initiate the shear bands.

The amorphous structure of the Mg-Cu-RE BMGs can be understood as composed by strong clusters embedded in a softer matrix. The reduction of the cluster fraction, which increases the softer area is observed to improve the ductility. This successful strategy can be extended to others BMGs to enhance their plastic behaviour, which will increase their potential for industrial applications.

\section{Conclusions}

The substitution of $\mathrm{Y}$ by $\mathrm{MM}$ in the $\mathrm{Mg}_{65} \mathrm{Cu}_{25} \mathrm{Y}_{10}$ decreases the glass forming ability and the crystallization temperature; but increases the microhardness of the amorphous phase and the crystallized alloy, having a very brittle behaviour.

The partial substitution of $\mathrm{Cu}$ by $\mathrm{Al}$ in the $\mathrm{Mg}_{65} \mathrm{Cu}_{25} \mathrm{MM}_{10}$ increases the crystallization temperature and shifts the whole phase transformation process to higher temperatures. The microhardness increases with the Al content in the amorphous alloys; however the Young's modulus doesn't have an appreciable change retaining a value of $\sim 55 \mathrm{GPa}$ for the amorphous alloys.

All the rapidly solidified samples showed brittle behaviour, however, the partial substitution of $\mathrm{Cu}$ by $\mathrm{Al}$ in the $\mathrm{Mg}_{65} \mathrm{Cu}_{25} \mathrm{MM}_{10}$ improves the ductility allowing the development of vein-patterns and small dimples during the shear sliding as are observed in the fracture surface.

\section{Acknowledgement}

This work was financially supported by PICT-Oxford 2010/2831 and UBACyT 20020130100663.

\section{References}

1. Inoue A, ed. Bulk Amorphous Alloys - Preparation and Fundamental Characteristics. Trans Tech Publications; 1998. 124p.

2. Park ES, Kang HG, Kim H, Kim WT, Kim DH. The effect of Ag addition on the glass-forming ability of $\mathrm{Mg}-\mathrm{Cu}-\mathrm{Y}$ metallic glass alloys. Journal of Non-Crystalline Solids. 2001;279(2-3):154-160.

3. Busch R, Liu W, Johnson W. Thermodynamics and kinetics of the $\mathrm{Mg}_{65} \mathrm{Cu}_{25} \mathrm{Y}_{10}$ bulk metallic glass forming liquid. Journal of Applied Physics. 1998;83(8):4134-4141.

4. Xi XK, Zhao DQ, Pan MX, Wang WH, Wu Y., and Lewandowski JJ. Fracture of Brittle Metallic Glasses: Brittleness or Plasticity. Phys. Rev. Lett. 2005; 94, 125510: 1-4.

5. Wang SG, Shi LL, Xu J. Mg-based bulk metallic glasses: Elastic properties and their correlations with toughness and glass transition temperature. Journal of Materials Research. 2011;26(7):923-933.

6. Bruck HA, Christman T, Rosakis AJ, Johnson WL. Quasistatic constitutive behaviour of $\mathrm{Zr}_{41.25} \mathrm{Ti}_{13.75} \mathrm{Ni}_{10} \mathrm{Cu}_{12.5} \mathrm{Be}_{22.5}$ bulk amorphous alloys. Scripta Metallurgica et Materialia. 1994;30(4):429-434.

7. Liu CT, Heatherly L, Horton JA, Easton DS, Carmichael CA, Wright JL, et al. Test Environments and Mechanical Properties of Zr-Base Bulk Amorphous Alloys. Metallurgical and Materials Transactions A. 1998;29(7):1811-1820. 
8. Pampillo CA, Chen HS. Comprehensive plastic deformation of a bulk metallic glass. Materials Science and Engineering. 1974;13(2):181-188.

9. Spaepen F. On the fracture morphology of metallic glasses. Acta Metallurgica. 1975;23(5):615-620.

10. Spaepen F. A microscopic mechanism for steady state inhomogeneous flow in metallic glasses. Acta Metallurgica. 1977;25(4):407-415.

11. Yokoyama Y. Ductility improvement of $\mathrm{Zr}-\mathrm{Cu}-\mathrm{Ni}-\mathrm{Al}$ glassy alloy. Journal of Non-Crystalline Solids. 2003;316(1):104-113.

12. Xu YK, Ma H, Xu J, Ma E. Mg-based bulk metallic glass composites with plasticity and gigapascal strength. Acta Materialia. 2005;53(6):1857-1866.

13. Ma H, Xu J, Ma E. Mg-based bulk metallic glass composites with plasticity and high strength. Applied Physics Letters. 2003;83(14):2793-2795.

14. Jang JS, Ciou JY, Hung TH, Huang JC, Du XH. Enhanced mechanical performance of $\mathrm{Mg}$ metallic glass with porous Mo particles. Applied Physics Letters. 2008;92(1):011930-3.

15. Kinaka M, Kato H, Hasegawa M, Inoue A. High specific strength Mg-based bulk metallic glass matrix composite highly ductilized by Ti dispersoid. Materials Science and Engineering: A. 2008;494(1-2):299-303.

16. Hui X, Dong W, Chen GL, Yao KF. Formation, microstructure and properties of long-period order structure reinforced Mg-based bulk metallic glass composites. Acta Materialia. 2007;55(3):907-920.

17. Chen HS, Krause JT, Coleman E. Elastic constants, hardness and their implications to flow properties of metallic glasses. Journal of Non-Crystalline Solids. 1975;18(2):157-171.

18. Lewandowski JJ, Wang WH, Greer AL. Intrinsic plasticity or brittleness of metallic glasses. Philosophical Magazine Letter. 2005;85(2):77-87.

19. Du XH, Huang JC, Hsieh KC, Chen HM, Jang JS, Liaw PK. Two-glassy-phase bulk metallic glass with remarkable plasticity. Applied Physics Letters. 2007;91:131901-131903.

20. Park BJ, Chang HJ, Kim DH, Kim WT. In situ formation of two amorphous phases by liquid phase separation in Y-Ti-Al-Co alloy. Applied Physics Letters. 2004;85(26):6353-6355.

21. Park ES, Kim DH. Phase separation and enhancement of plasticity in $\mathrm{Cu}-\mathrm{Zr}-\mathrm{Al}-\mathrm{Y}$ bulk metallic glasses. Acta Materialia. 2006;54(10):2597-2604.

22. Audebert F, Rozenberg S, Galano M. Rapidly quenched $\mathrm{Mg}_{65} \mathrm{Al}_{\mathrm{x}} \mathrm{Cu}_{25-\mathrm{x}} \mathrm{MM}_{10}$ (MM: mischmetal) alloys. Journal of Non-Crystalline Solids. 2001;287(1-3):45-49.

23. Audebert F, Mendive C, Vidal A. Structure and mechanical behaviour of Al-Fe-X and Al-Ni-X rapidly solidified alloys. Materials Science and Engineering: A. 2004;375-377:1196-1200.
24. Audebert F, Sirkin H, García-Escorial A. Approach to the atomic structure of amorphous Al-Fe-Nb. Philosophical Magazine B: Physics of Condensed Matter. 1997;76(4):483-487.

25. Audebert F. Amorphous and Nanostructured Al-Fe and Al-Ni Based Alloys. In: Idzikowski B, Švec P, Miglierini M, eds. Properties and Applications of Nanocrystalline Alloys from Amorphous Precursors - NATO Science Series. Dordrecht: Kluwer; 2005. p.301-312.

26. Saporiti F, Boudard M, Audebert F. Short range order in Al-Fe$\mathrm{Nb}, \mathrm{Al}-\mathrm{Fe}-\mathrm{Ce}$ and Al-Ni-Ce metallic glasses. Journal of Alloys and Compounds. 2010;495(2):309-312.

27. Audebert F, Galano M, Saporiti F. The use of $\mathrm{Nb}$ in Rapid Solidified Al alloys and Composites. Journal of Alloys and Compounds. 2014;615(Suppl.1):S621-S626.

28. Lukens WE, Wagner CNJ. A comparison between the structures of amorphous and liquid Ag-Cu and $\mathrm{Cu}-\mathrm{Mg}$ alloys. Journal of Applied Crystallography. 1976;9:159-168.

29. Nassif E, Lamparter P, Steeb S. X-ray diffraction study on the structure of the metallic glasses $\mathrm{Mg}_{84} \mathrm{Ni}_{16}$ and $\mathrm{Mg}_{30} \mathrm{Ca}_{70}$. Zeitschrift fur Naturforschung $a$. 1983;38(11):1206-1209.

30. Nowosielski R, Babilas R, Guwer A, Gawlas-Mucha A, Borowski A. Fabrication of $\mathrm{Mg}_{65} \mathrm{Cu}_{25} \mathrm{Y}_{10}$ bulk metallic glasses. Archives of Materials Science and Engineering. 2012;53(2):77-84.

31. Wang JQ, Yu P, Bai HY. Minor addition induced enhancement of strength of Mg-based bulk metallic glass. Journal of NonCrystalline Solids. 2008;354(52-54):5440-5443.

32. Geng JY, Sun YF, Wang LG, Zhu SJ, Liu LZ, Guan SK. Effect of $\mathrm{A} 1$ addition on formation and mechanical properties of $\mathrm{Mg}$ $\mathrm{Cu}-\mathrm{Gd}$ bulk metallic glass. Transactions of Nonferrous Metals Society of China. 2007;17(5):907-912.

33. Huang K, Chen G, Zhao YT, Wang G, Shao Y. Crystallization microstructure of $\mathrm{Mg}_{65} \mathrm{Cu}_{25} \mathrm{Y}_{10}$ bulk amorphous alloy. Transactions of Nonferrous Metals Society of China. 2012;22(4):831-836.

34. Chen G, Ferry M. Crystallization and thermally induced surface relief effects in a $\mathrm{Mg}_{65} \mathrm{Cu}_{25} \mathrm{Y}_{10}$ bulk metallic glass. Journal of Materials Science. 2007;42(2):646-651.

35. Murty B, Hono K. Formation of Nanocrystalline Particles in Glassy Matrix in Melt-Spun Mg-Cu-Y Based Alloys. Materials Transactions, JIM. 2000;41(11):1538-1544.

36. Zheng Q, Ma H, Ma E, Xu J. Mg-Cu-(Y, Nd) pseudo-ternary bulk metallic glasses: The effects of $\mathrm{Nd}$ on glass-forming ability and plasticity. Scripta Materialia. 2006;55(6):541-544.

37. Castellero A, Moser B, Uhlenhaut DI, Dalla Torre FH, Löffler JF. Room-temperature creep and structural relaxation of $\mathrm{Mg}-\mathrm{Cu}-\mathrm{Y}$ metallic glasses. Acta Materialia. 2008;56(15):3777-3785.

38. Pineda E, Bruna P, Ruta B, Gonzalez-Silveira M, Crespo D. Relaxation of rapidly quenched metallic glasses: Effect of the relaxation state on the slow low temperature dynamics. Acta Materialia. 2013;61(8):3002-3011.

39. Schuh CA, Lund AC. Atomistic basis for the plastic yield criterion of metallic glass. Nature Materials. 2003;2(7):449-452. 